\title{
Factors in child burn and scald accidents in Bradford 1969-73
}

\author{
ALYSON LEARMONTH \\ From the School of Science and Society, University of Bradford
}

SUMMARY A study has been undertaken of burn and scald accidents to children in Bradford. In the first part, 1577 accidents treated in the Bradford Royal Infirmary between 1969 and 1973 were analysed by city ward of residence of the patient and these were correlated with 14 social and demographic characteristics of the wards. A correlation was found between burn and scald accidents and New Commonwealth immigrants and overcrowding. In the second part, 78 families at the burns clinic were interviewed. Similar patterns to those in the larger study were found. Although clinical impressions emerged concerning the details of the accidents the interviews did not provide any explanation for the main findings.

There is some evidence to suggest that people in the lower socioeconomic categories are more likely to suffer burns and scalds. This has been documented for accidents in general (Wedge and Prosser, 1973) and for burns and scalds in particular (Martin, 1970; Wilkinson, 1970). The aim of this study is to elucidate this relationship, combining large-scale statistical analysis with a small-scale detailed survey.

It has recently been suggested (Scott-Samuel, 1977) that techniques of social area analysis may be usefully applied in community medicine, for example, to.identify factors in the aetiology of a disease. The first part of this study uses similar techniques to investigate the distribution of child burn and scald accidents in Bradford.

An understanding of why particular factors are associated with burns and scalds can be reached only through studying the processes involved in each accident. In order to provide a picture of accident occurrence from this viewpoint, a series of interviews was undertaken in the second part of the study.

To limit the type of hazards being considered, children under 12 were selected as a group at high risk of home accidents. The hospital was used as the data source for both parts of the study, although it was recognised that this might bias the figures.

\section{LARGE SCALE ANALYSIS}

\section{Method}

1577 cases from Bradford Royal Infirmary casualty register (1969-73) were analysed by address and time of accident reporting. The following procedures were then carried out:

1. An accident index was calculated as the ratio between observed and expected numbers of burns and scalds, for each city ward. The expected number was age-adjusted in each ward. Enumeration districts were rejected as an area base because the number of accidents in each was too small. Fourteen social indices (listed in the Table) were chosen from the 1971 census in the light of the results of a pilot study. A correlation matrix was produced.

2. A linear stepwise regression was carried out using program BMD 02R (NAG-NIMBUS Manual, 1973; Dixon, 1973).

3. A factor analysis was carried out using program BMD NO8M (NAG-NIMBUS Manual, 1973; Dixon, 1973).

4. Times of accident occurrence were related to results in the literature. A correlation between burns and average weekly and monthly temperatures was carried out but scalds were not studied in this way because they were not thought to be seasonal.

\section{Results}

The ratio of observed to expected numbers of burns and scalds was plotted on a map of the city showing isolines for this ratio. In the outer suburbs the ratio was 0.50 but in the inner city it was over 1.50 with a maximum of over 2.0 in an area close to but not including the hospital. The matrix showed considerable correlation among the 14 social indices. The most significant correlations were: New 
Table Fourteen socioeconomic indices selected from the 1971 census

LIVING CONDITIONS*

Number/1000 households that share/lack hot water

Number $/ 1000$ households with more than 1.5 people per room (overcrowding)

Number/1000 houses which are council owned

Number/1000 houses which are owner-occupied

ACCESS TO HOSPITAL*

Number/1000 households with no car

NEW COMMONWEALTH IMMIGRANTS**

Number/1000 present residents with both parents born in the New Commonwealth

EDUCATION***

Number/1000 residents with ONC, school certificate, HNC, HND, or degree

Number $/ 1000$ persons in private households who are students over 15

SOCIOECONOMIC GROUP***

Heads of household/1000 employed as junior non-manual workers, personal service workers, semi- or un-skilled manual workers (low socioeconomic group)

Heads of household/1000 employed as employers, managers, self-employed or employed professional workers

ECONOMIC DISTURBANCE***

Number/1000 economically active persons not in employment

Number/1000 economically active persons with an occupational change in the last year

WORKING MOTHERS***

Number $/ 100$ households with a child under five where the mother works full-time

Number $/ 100$ households with a child under five where the mother works part-time

* Office of Population Censuses and Surveys (1972b)

* Office of Population Censuses and Surveys (1972a)

*** Office of Population Censuses and Surveys (1973).

Commonwealth immigrants with lack of hot water, overcrowding, and low socioeconomic group; and high socioeconomic group with education. The accident index was most highly correlated with lack of hot water, overcrowding, and immigrants.

The linear stepwise regression showed that the burn and scald index could best be accounted for by an equation including New Commonwealth immigrants, lack of hot water, council housing, lack of car, educational standard, and mothers working part-time. Of these, New Commonwealth immigrants accounted for the largest part of the variance. When the programme was re-run excluding New Commonwealth immigrants from the list of variables, overcrowding alone provided the best equation. Because of its close correlation with immigrants, much of the variance accounted for by overcrowding was also accounted for by immigrants, and this did not emerge on the first run.

However, the factor analysis failed to identify a single factor underlying New Commonwealth immigrants, overcrowding, and burn and scald accidents. The first factor extracted could possibly be related to poverty, but was too general to be useful. Factor 2 could be related to housing, since council housing emerges with a high positive loading and owner-occupied housing with a high negative loading; however, the accident index does not have a significant loading. Factor 3 is more difficult to interpret. It has high positive loadings with education, unemployment, and students in its unrotated form, and with lack of car and low socioeconomic group in its rotated form. Factor 4 may be related to mother's occupation. The accident index does not have a significant loading with either factor 3 or factor 4 .

The four factors were also considered in relation to each ward. The most notable feature was that Manningham ward emerged as unique, with a high loading for all four factors, but the other wards do not fall easily into groups. It might be expected that the six inner city wards, with their high proportion of old housing and immigrants, would be grouped together, that the five wards with more than $40 \%$ council housing might be similar, and that the inner commuter belt would form another set. That this does not occur with the factors derived from the 14 indices used here may indicate that the ward is too large an area for a city such as Bradford with diversity of housing in small areas.

The patterns of accidents by age and by time confirm those established in the literature (MacQueen, 1960; British Medical Association, 1964). The most vulnerable age is $1-2$ years, with a significantly higher rate for males than females; seasonal incidence shows a peak in November and February but not in midwinter, and this is more marked for burns than for scalds; peak time of occurrence is $18 \cdot 00-19 \cdot 00$, with a secondary peak for burns from 15.00-16.00 and for scalds from $11 \cdot 00-12 \cdot 00$.

On the seasonal incidence of burns, the correlation with average weekly temperatures was significant with $5 \%$ probability, and with average monthly temperatures with $0 \cdot 1 \%$ probability. A multiple regression of burns with average weekly minimum temperatures and wind speed did not produce significant results. It appears that the burn rate is related to general weather conditions rather than short-term fluctuations. This does not help to explain why the highest numbers of accidents occur in February and November rather than in midwinter.

SMALL-SCALE ANALYSIS

\section{Method}

The final version of the questionnaire, answered by 78 people whose children had a burn or scald, was 
administered in the burns clinic, and was necessarily brief. The range of information extracted is considered here in four categories: agent of injury and how the accident occurred; distribution in time (time, day, season, age of child), which is directly comparable with the large-scale study; background information which can be indirectly compared with the large-scale study; and other background information.

The possibility of using a matched 'control' group who had not had accidents was explored, but abandoned in the face of problems of valid matching.

In almost $25 \%$ of the accidents the child pulled cups of hot drinks off tables, washing machines, television sets, or other surfaces. Another $5 \%$ were caused by children running into people carrying hot cups of tea. The only case in which a child was passively involved in an accident with a hot drink was when the mother knocked over a cup of coffee and spilt it on the child playing at her feet. In this particular accident the mother definitely associated her clumsiness with premenstrual tension: she had broken a set of glasses earlier in the day.

After cups of hot drink, pans and teapots caused most scalds (13\% and $9 \%$ respectively). While more of the pans were knocked over or fallen against, teapot accidents followed a similar pattern to cups of hot drink; most were pulled over. Kettles accounted for only $3 \%$ of accidents, but these are perhaps more likely to cause serious injury. In the study by Yeats $e t$ al. (1974) kettles were selected as a relatively common cause of injury with a high cost in terms of medical care.

Contact with a fire or heater caused $13 \%$ of accidents: four from gas fires; three from open fires; two from electric fires; and one from a stove. In all the accidents with gas and electric fires the child fell against the guard, so these could have been worse .... in only one did the guard fall off and the child's knee actually go into the fire.

The most common days for accidents were at the weekend. Sixteen per cent of the accidents happened when the family was visiting or being visited, which often happens on a Saturday or Sunday. Various reasons for this were put forward by parents. The child gets excited and runs about (in three cases children bumped into someone holding a cup of tea); the room becomes crowded so that things are more easily knocked over; when visiting there may not be a fireguard which the child is used to at home; or a normal routine is disturbed, such as hooking a kettle flex out of reach, or fastening the baby in its pram while hot things are around. However, most mothers thought that the accident could have happened at any time.
As in the study of the casualty register, the peak time of occurrence was $18 \cdot 00-19 \cdot 00$. In three cases the mother specifically associated the accident with the rush before tea or before going out to work in the evening, but this does not explain why there is not an equivalent breakfast peak, because at that time many similar factors are at work. This distribution is confirmed by the Department of Prices and Consumer Protection survey (1977). (It should be noted that the large-scale analysis was based on time of reporting, while the interviews discovered the time of occurrence).

Age distribution reflects the preponderance of one- to three-year-olds found earlier; at these ages a child is first exploring his or her environment. In four cases the accident occurred because the child was developing so fast that he or she could reach surfaces the parents still regarded as 'safe'. Eight mothers associated the accident with the child being 'lively' or 'adventurous'.

Four aspects which relate to the social indices used in the large-scale study can be considered by comparing the accident population in the interviews with that of Bradford as a whole:

(1) $30.7 \%$ of the accident population were immigrants (from all over the world), compared with $10.8 \%$ of the population of Bradford (Office of Population Censuses and Surveys, 1972a). However, this does not allow for probable differences in the age structure of the populations.

(2) $4 \%$ of the accident population were living at densities of over 1.5 people per room, compared with $3 \%$ of the population of Bradford (Office of Population Censuses and Surveys, 1972b). The difference is not significant, so the high correlation with overcrowding found in the large-scale study is not substantiated. In the interviews two parents attributed the accident partly to the room being crowded, but in both accidents visitors were involved.

(3) The interview sample contained a higher proportion of heads of households who were skilled, semi-skilled, or unskilled manual workers than in the total population; this sample also contained a high percentage $(9 \cdot 3 \%)$ of families where the father was dead or had separated from his wife.

(4) $41 \%$ of the mothers had left school at the age of $15,20 \%$ at 16 , and $22 \%$ at 17 . Sixteen per cent, all Pakistani women, had had no schooling, although one or two were attending evening classes in English. No comparable figures for the overall population have been found. There was no strong negative correlation with education in the casualty register analysis.

Finally there are four other points which may be of interest. (1) $34 \%$ of the interview sample had families with three or more children, compared with 
$29 \%$ of the population (Office of Population Censuses and Surveys, 1972a). Two cases illustrate the risks associated with larger families: in one, the mother found it hard to impress on her teenage children the hazards associated with a toddler; in the other, an eight-year-old was in charge of changing the younger children for bed. (2) Accidents do not appear to be associated with young mothers. There may be an interaction of factors in that older women with young children are likely to have larger families, increasing the risks, although their own experience and maturity reduce them. (3) In only $14 \%$ of the accidents was no adult present, and in $66 \%$ the mother was in the room. (4) Two parents considered stress a contributory factor to the accident, while another three reported illness in the family without connecting the two things.

\section{Conclusions}

The large-scale study indicated a connection between burn and scald accidents in children, overcrowding, and New Commonwealth immigrants. However, the techniques used did not elucidate the relationship further. One reason for this could be that the ward is too large an area for analysis, although the enumeration district is too small. A second reason could be the distortion produced by using only hospital data to measure accident occurrence. The most vulnerable age was one to two years, boys were more frequently involved than girls, the peak time of day was $18 \cdot 00-19 \cdot 00$, and the peak season was winter.

The small-scale study was intended to give an insight into the accident processes which produce the large-scale pattern. On the whole it does substantiate them. Although $30.7 \%$ of the interviews (24) were with immigrant families, this was not enough for common factors to emerge. However, it does serve a useful function in reminding us of the complexity of the real life situation, compared with the simplicity of a matrix of indices.
The use of large-scale analysis on an area basis and the study of case histories as complementary tools in accident research may be fruitful.

The project was funded by a Science Research Council grant and a full account has been submitted as a PhD thesis to the University of Bradford.

Reprints from Dr. A. M. Learmonth, Health Education Section, Oldham Area Health Authority, St. Peter's House, Oldham OL1 1JJ.

\section{References}

British Medical Association (1964). Accidents in the Home. British Medical Association: London.

Dixon, W. J. (1973). BMD Biomedical Computer Programs. University of California Press: Berkeley.

Department of Prices and Consumer Protection (1977). The Home Accident Surveillance System: a report of the first six months data collection. Consumer Safety Unit: London.

MacQueen, I. (1960), A study of home accidents in Aberdeen. Churchill Livingstone: Edinburgh.

Martin, H. L. (1970). The contribution of housing conditions to burns and scalds in children The Medical Officer, 175, 281-282.

NAG-NIMBUS Manual Release 2 (1973). Nineteen Hundred Series Implementation of the BMD UCLA Statistical Program. Numerical Algorithms Group Ltd: Oxford.

Office of Population Censuses and Surveys (1972a). 1971 Census Small Area Statistics Ward Library 100\% Population. HMSO: London.

Office of Population Censuses and Surveys (1972b). 1971 Census Small Area Statistics Ward Library 100\% Households. HMSO: London.

Office of Population Censuses and Surveys (1973). 1971 Census Small Area Statistics Ward Library 10\% Migration and Economic Activity. HMSO: London.

Scott-Samuel, A. (1977). Social area analysis in community medicine. British Journal of Preventive and Social Medicine, 31, 199-204.

Wedge, P., and Prosser, H. (1973). Born to fail. Arrow Books: London.

Wilkinson, A. W. (1970). Burns Community Health (Bristol), 2, 23-28.

Yeats, K., Roberts, J. L., and Dale, J. W. (1974). Studies of Home Accidents: Health Education and Kettle Accidents. Health Education Council Medical Research Division Report No. 120. Health Education Council: London. 